\title{
Chloride Transport in Undersea Concrete Tunnel
}

\author{
Yuanzhu Zhang, ${ }^{1}$ Xiaozhen $\mathrm{Li}^{2}$ and Guohua $\mathrm{Yu}^{1}$ \\ ${ }^{1}$ Department of Civil Engineering, Zhejiang University City College, Hangzhou, Zhejiang 310015, China \\ ${ }^{2}$ Architecture Engineering College, Jinhua Polytechnic, Jinhua, Zhejiang 321017, China
}

Correspondence should be addressed to Yuanzhu Zhang; zhangyz@zucc.edu.cn

Received 25 November 2015; Accepted 5 May 2016

Academic Editor: Seung-Jun Kwon

Copyright (C) 2016 Yuanzhu Zhang et al. This is an open access article distributed under the Creative Commons Attribution License, which permits unrestricted use, distribution, and reproduction in any medium, provided the original work is properly cited.

\begin{abstract}
Based on water penetration in unsaturated concrete of underwater tunnel, a diffusion-advection theoretical model of chloride in undersea concrete tunnel was proposed. The basic parameters including porosity, saturated hydraulic conductivity, chloride diffusion coefficient, initial water saturation, and moisture retention function of concrete specimens with two water-binder ratios were determined through lab-scale experiments. The variation of chloride concentration with pressuring time, location, solution concentration, initial saturation, hydraulic pressure, and water-binder ratio was investigated through chloride transport tests under external water pressure. In addition, the change and distribution of chloride concentration of isothermal horizontal flow were numerically analyzed using TOUGH2 software. The results show that chloride transport in unsaturated concrete under external water pressure is a combined effect of diffusion and advection instead of diffusion. Chloride concentration increased with increasing solution concentration for diffusion and increased with an increase in water pressure and a decrease in initial saturation for advection. The dominant driving force converted with time and saturation. When predicting the service life of undersea concrete tunnel, it is suggested that advection is taken into consideration; otherwise the durability tends to be unsafe.
\end{abstract}

\section{Introduction}

With the urgent need for water transportation, subsea concrete tunnels gradually became the priority mode of crossing sea during the past few years in China. Xiamen Xiangan tunnel is the first undersea tunnel in Chinese mainland in 2011; after that Qingdao Jiaozhou bay subsea tunnel and Hong Kong-Zhuhai-Macao subsea tunnel are successively constructed. However, booming developments of subsea tunnels have to face the challenge to meet the requirement of service life over 100 years because of the erosion of pressure seawater on tunnels.

For a long time, underwater concrete structures withstanding high hydrostatic pressure are usually viewed as fully saturated concrete [1]. Based on the hypothesis, most researchers only considered diffusion of chloride ions and used Fick's diffusion laws to predict the service life of undersea tunnels [2-4]. However cement-based materials difficultly reach full saturation in fact. Powers and Brownyand [5] first proposed that cementitious materials were unsaturated through $220 \mathrm{~d}$ immersion tests of plain cement prisms.
Afterwards, further studies on the relative humidity in concrete successively verified the unsaturated characteristics of concrete through laboratory experiments [6-8]. Recently, concrete coring tests of underwater projects in Denmark and Sweden also showed that most regions of concrete core samples were still unsaturated except near-surface zone; even the structures have served for decades [9]. Thus, chloride transport in undersea concrete structures especially for the low permeability structures made of high performance concrete should be treated as flow in unsaturated porous materials; that is, advection of chloride due to the motion of pore solution in unsaturated concrete should also be taken into account besides diffusion.

Most of existing studies about chloride diffusion-advection in concrete were focused on superstructures, in which governing equations of diffusion-advection models under drying, wetting, or repeated drying-wetting environments were established by taking relative humidity $H$ or saturation $s$ as basic variable and the influences of different factors such as time and solution concentration were discussed without considering hydraulic pressure [10-13]. However, underwater 
tunnels withstand a large pressure difference between inside wall and outside wall. Jin et al. [14] found that external water pressure had a significant influence on chloride transport through laboratory experiments and Chen's experiments also proved the effect of water pressure on chloride motion in concrete [15], while they still took the fully saturated concrete assumptions to analyze the transport process. Zhang et al. confirmed the combined affection of capillary suction and water pressure on the motion of pore solution of unsaturated concrete based on laboratory experiments and numerical simulations [16]. As a result, we think that the advection of chloride ions with the movement of pore solution in undersea tunnel is correspondingly driven by both the effects.

Based on water penetration research in concrete of underwater tunnel [16], a diffusion-advection theoretical model of chloride in undersea concrete tunnel was proposed, and the variation of chloride concentration with pressuring time, location, solution concentration, initial saturation, hydraulic pressure, and water-binder ratio was investigated through laboratory tests under external water pressure. In addition, the distribution and change of chloride concentration of isothermal horizontal flow were numerically analyzed using TOUGH2 (Transport of Unsaturated Groundwater and Heat) software and different transport models were compared. The research is helpful to improvement of the service life prediction model of undersea concrete tunnel.

\section{Theoretical Basis}

2.1. Chloride Transport by Diffusion in Concrete. Diffusion results in chloride ions transport from the regions of high ions concentration to the regions of lower ions concentration.

Under steady-state condition, diffusion flux of free chloride ions is usually described by Fick's 1st diffusion law as follows:

$$
J_{d}=-D \nabla C_{f}
$$

where $J_{d}$ is the diffusion flux of free chloride ions, $\mathrm{kg} /\left(\mathrm{m}^{2} \mathrm{~s}\right) ; D$ is the chloride diffusion coefficient of concrete, $\mathrm{m}^{2} / \mathrm{s} ; \nabla$ is the nabla operator; $C_{f}$ is the volume concentration of free chloride dissolved in pore solution, $\mathrm{kg} / \mathrm{m}^{3}$; the negative sign in (1) indicates that diffusion occurs with the concentration reduction.

If chloride concentration changes with time (i.e., nonsteady diffusion condition), chloride movement can be described by Fick's 2nd diffusion law as

$$
\frac{\partial C_{f}}{\partial t}=-\nabla J_{d}
$$

where $t$ is the diffusion time, s.

However concrete is not a homogeneous isotropic material to satisfy the hypothesis of Fick's diffusion laws; hence the effective diffusion coefficient $D_{\text {eff }}$ is used to replace $D$ in (1). Many researchers have devoted their efforts to studying $D_{\text {eff }}$ of concrete. The studies generally believed that $D_{\text {eff }}$ depended not only on the test method, but also on the factors such as service time, saturated degree, and temperature of concrete. Atkinson and Nickerson [17] proposed a model as follows:

$$
D_{\text {eff }}=D_{s_{0}} \phi \beta \text {, }
$$

where $D_{s_{0}}$ is the chloride diffusion coefficient in saturated concrete, $\mathrm{m}^{2} / \mathrm{s} ; \phi$ is the porosity; $\beta$ is a pore structure parameter which can be obtained from Millington-Quirk model [18]:

$$
\beta=\phi^{1 / 3} s^{10 / 3},
$$

where $s$ is the saturated degree.

2.2. Chloride Transport by Advection in Concrete. Advection means ions transport due to the carrier fluid's bulk motion. The advection flux can be expressed as

$$
J_{a}=-C_{f} \mathbf{u}
$$

where $J_{a}$ is the advection flux of free chloride ions, $\mathrm{kg} /\left(\mathrm{m}^{2} \mathrm{~s}\right)$; $\mathbf{u}$ is the fluid velocity, $\mathrm{m} / \mathrm{s}$.

The fluid movement in capillary pores of saturated concrete is driven by hydraulic head difference (i.e., water pressure difference), which can be described by Darcy's law as follows:

$$
\mathbf{u}=-K_{s} \nabla H=-\frac{K_{s}}{\rho_{w} g} \nabla P
$$

where $K_{s}$ is the saturated hydraulic conductivity, $\mathrm{m} / \mathrm{s} ; H$ is the hydraulic head, $\mathrm{m} ; \rho_{w}$ is the water density, $\mathrm{kg} / \mathrm{m}^{3} ; g$ is the acceleration of gravity, $\mathrm{m} / \mathrm{s}^{2} ; P$ is the hydraulic pressure of the flow path, Pa.

Based on Darcy's law, Richards proposed motion equation of water in unsaturated soils in 1931, namely, Richards' equation:

$$
\mathbf{u}=-K(\theta) \nabla \psi=-\frac{K_{s}}{\rho_{w} g} k_{r}(\theta) \nabla \psi,
$$

where $\theta$ is the water content; $K(\theta)$ is the unsaturated hydraulic conductivity, $\mathrm{m} / \mathrm{s} ; \psi$ is the total driving potential, $\mathrm{Pa} ; k_{r}$ is the relative hydraulic conductivity, and it ranges between 0 (dry state) and 1 (saturated state), which is commonly represented by Van Genuchten-Mualem model [19-21]:

$$
\begin{aligned}
k_{r}(s) & =s^{0.5}\left[1-\left(1-\frac{1}{s^{m}}\right)^{m}\right]^{2}, \\
s & =\frac{\theta-\theta_{r}}{\theta_{s}-\theta_{r}},
\end{aligned}
$$

where $\theta_{r}$ is the residual water content; $\theta_{s}$ is the saturated water content; and $m$ is an empirical material parameter which can be fitted by experimental data.

Because the temperature of underwater is generally constant, isothermal transport is considered for the advection model; thus the total driving potential includes matric potential $\psi_{m}$, pressure potential $\psi_{p}$, and gravity potential $\psi_{g}$. 
Matric potential $\psi_{m}$ can be viewed as capillary suction of porous materials. It is negative and generally described by Van Genuchten-Mualem model [19-21] as follows:

$$
\psi_{m}=-\alpha\left(s^{-1 / m}-1\right)^{1-m},
$$

where $\alpha$ is an empirical factor fitted by experimental data.

Pressure potential $\psi_{p}$ is caused by the difference of pressure in pressure field. For undersea concrete tunnel, the outer surface contacts hydraulic water while the inner surface contacts atmosphere. Considering the connectivity of capillary pores, it is assumed that the air in unsaturated pores directly connects with external atmosphere; thus the pore solution in unsaturated zone is subjected to atmospheric pressure without additional hydrostatic pressure. However, the pore solution in saturated zone directly connects with external hydraulic water, so it is subjected to the additional hydrostatic pressure which depends on the surface pressure and location [22]. Therefore, pressure potential can be calculated by

$$
\begin{aligned}
\psi_{p} & =0 \quad(0 \leqslant s<1) \\
\psi_{p}(x, t) & =P_{0} \operatorname{erfc}\left(\frac{x}{2} \sqrt{\frac{\rho_{w} g}{K_{s} E t}}\right) \quad(s=1),
\end{aligned}
$$

where $P_{0}$ is the external water pressure on the surface, $\mathrm{Pa}$; erfc is the complementary error function; $x$ is the distance from the exposed surface, $\mathrm{m}$; $E$ is the bulk modulus, Pa.

Gravity potential $\psi_{g}$ is equal to the work that per unit volume of water is moved from its location to a fixed reference location, which can be described as

$$
\psi_{g}= \pm \rho_{w} g z
$$

where $z$ is the distance from the fixed reference location, $\mathrm{m}$.

\subsection{Chloride Transport by Diffusion-Advection in Concrete} of Undersea Tunnel. With continuous seawater ingress into undersea tunnel, initial unsaturated zone near the inlet surface gradually reaches full saturation. In saturated zone, $\psi_{m}=0, \psi_{p}>0$, water motion is mostly controlled by pressure potential, while in unsaturated zone, $\psi_{p}=0, \psi_{m}<$ 0 , water motion is mostly controlled by matric potential. So chloride transport in undersea tunnel is combined driven by diffusion and advection, which are driven by the difference of concentration and driving potentials converted with saturation, respectively. As a matter of fact, a part of chloride ions will combine to binding chloride $C_{b}$ by chemical reaction and physical bond. After the ion-combination reaction, residual free chloride ions transport in concrete by diffusion and advection which can be expressed as follows:

$$
J_{\mathrm{cl}}=J_{d}+J_{a}
$$

where $J_{\mathrm{cl}}$ is the total flux of free chloride ions, $\mathrm{kg} /\left(\mathrm{m}^{2} \mathrm{~s}\right)$.

Ogata and Banks [23] have proposed an analytic solution for the diffusion-advection function under saturated state, but under unsaturated state the complicated partial differential equation (13) has to be solved by finite difference method or finite element method.
TABLE 1: Mix proportion of concrete.

\begin{tabular}{lcccccc}
\hline \multirow{2}{*}{ Specimens number $w / b$} & \multicolumn{5}{c}{ Mix proportion $/\left(\mathrm{kg} / \mathrm{m}^{3}\right)$} \\
& & Cement & Fly ash & Water & Sand & Gravel \\
\hline BI & 0.36 & 419 & 46 & 168 & 532 & 1241 \\
BII & 0.40 & 379 & 42 & 168 & 542 & 1266 \\
\hline
\end{tabular}

TABLE 2: Strength, porosity, saturated hydraulic conductivity, and chloride diffusion coefficient of the specimens.

\begin{tabular}{lcccc}
\hline Number & $f_{\mathrm{cu}, k} / \mathrm{MPa}$ & $\phi / \%$ & $K_{s} /(\mathrm{m} / \mathrm{s})$ & $D_{\mathrm{RCM}}\left(\mathrm{m}^{2} / \mathrm{s}\right)$ \\
\hline BI & 45.3 & 8.6 & $1.8 \times 10^{-11}$ & $4.0 \times 10^{-12}$ \\
BII & 44.7 & 9 & $2.2 \times 10^{-11}$ & $4.4 \times 10^{-12}$ \\
\hline
\end{tabular}

\section{Experiment Research}

Concrete specimens with two different water-binder ratios $(w / b)$ of 0.36 and 0.4 were prepared in our experiments (Table 1).

\subsection{Strength, Porosity, Saturated Hydraulic Conductivity, and} Chloride Diffusion Coefficient. The cube compressive strength $\left(f_{\mathrm{cu}, k}\right)$, porosity $(\phi)$, and saturated hydraulic conductivity $\left(K_{s}\right)$ of the concrete specimens were carried out in accordance with standards GB/T50081-2002 [24], ASTMC642-97(2002) [25], and SL352-2006 [26], respectively. Some methods are recommended for measuring chloride diffusion coefficient, from which we choose RCM method in accordance with standard GB/T 50082-2009 [27]. The results are shown in Table 2.

3.2. Initial Saturation of the Specimens. In order to analyze the effect of water saturation on chloride transport in concrete, three initial states were designed: natural state and being oven dried at $105^{\circ} \mathrm{C}$ for $1 \mathrm{~h}$ and $8 \mathrm{~h}$. First, the mass of the concrete specimen (the specimen information will be introduced in Section 3.4) at initial state was measured as $m_{0}$ by an electronic balance with an accuracy of $0.001 \mathrm{~g}$. Then, the specimen was oven dried at $105^{\circ} \mathrm{C}$ for $48 \mathrm{~h}$ to weigh the residual mass $m_{r}$. After that, the specimen was taken out from oven and fully immersed into water. The mass of the specimen was measured daily until it became constant, and the mass was taken as fully saturated mass $m_{s}$. Finally, initial saturation $\left(s_{0}\right)$ of the specimen can be determined by (14) and the results are shown in Table 3:

$$
s=\frac{m_{0}-m_{r}}{m_{s}-m_{r}}
$$

From Table 3 we can find that the initial saturation of $\mathrm{BI}$ and saturation of BII are all about 0.71 , which indicates that these concrete specimens are under unsaturated state. Meanwhile, BI with lower $w / b$ has lower saturation than BII. It is because more water was consumed for hydration reaction with higher dosages of cement, correspondingly less water left in capillary pores after hydration. In addition, the results show that concrete saturation dramatically declined after oven drying. The lower the saturation of specimens before drying, the longer the time it takes to decline the saturation. 
TABLE 3: Initial saturation of the specimens.

\begin{tabular}{lccc}
\hline Number & $w / b$ & Condition & $s_{0}$ \\
\hline BI & 0.36 & Natural state & 0.715 \\
BII-1 & 0.40 & Natural state & 0.718 \\
BII-2 & 0.40 & Oven dried for $1 \mathrm{~h}$ & 0.441 \\
BII-3 & 0.40 & Oven dried for $8 \mathrm{~h}$ & 0.312 \\
\hline
\end{tabular}

TABLE 4: Humidity control for isotherm adsorption test/\%.

\begin{tabular}{lcccccc}
\hline \multirow{2}{*}{ Condition } & \multicolumn{5}{c}{ Saturated salt solutions } & \multirow{2}{*}{ Water } \\
& $\mathrm{LiCl}$ & $\mathrm{MgCl}_{2}$ & $\mathrm{NaBr}$ & $\mathrm{NaCl}$ & $\mathrm{KCl}$ & \\
\hline Theoretic & 11.3 & 33.1 & 59.1 & 75.5 & 85.1 & 100 \\
Measured & 14.7 & 39.3 & 55.7 & 70.5 & 78.4 & 98 \\
\hline
\end{tabular}

3.3. Isothermal Adsorption of the Specimens. Cubic specimens with length of $100 \mathrm{~mm}$ were cast from the concrete mixes of Table 1. After being cured for 7 days in water, the specimens were taken out and cut into $50 \mathrm{~mm} \times 30 \mathrm{~mm} \times 30 \mathrm{~mm}$ cores by removing the surface layer. Each core then was cut into three slices with $10 \mathrm{~mm}$ thickness and kept on curing in water until 60 days. Then the mass of each slice was measured as $m_{s}$ and $m_{r}$ was measured after being oven dried according to Section 3.2. The adsorption environments were created by means of saturated salt solutions and water as shown in Table 4 . Then the three dried slices which were divided from the same core were hung together in sealed plastic bottles with different relative moisture solutions. A relative humidity probe with an accuracy of $\pm 1 \%$ was placed in the bottle top to measure the actual relative humidity inside the humidity bottle. The slice mass was measured daily until it became stable and then took it as $m_{0}$. The whole adsorption process took about $120 \mathrm{~d}$ to reach equilibrium state which is consistent with the existing literature [28]. Finally saturation can be calculated according to (14) and average saturation of three slices in the same bottle was taken as typical saturation for the environmental humidity. Thus, we plotted isothermal adsorption curves as Figure 1. Characteristic curves of moisture could correspondingly be plotted (Figure 2) according to gas-liquid equilibrium equation (see (15)), and relevant parameters were fitted with the characteristic curves (Table 5):

$$
\psi_{m}=-\frac{\rho_{w} R T}{M_{w}} \ln H,
$$

where $R$ is the ideal gas constant; $T$ is the temperature of the liquid phase in Kelvin, $\mathrm{K} ; M_{w}$ is the molecular weight of water, $\mathrm{kg} / \mathrm{mol}$; and $H$ is the relative humidity, $\%$.

3.4. Chloride Transport Test under Hydraulic Pressure. The device shown in Figure 3 was used for chloride transport test under hydraulic pressure. The cylindrical concrete specimen is $200 \mathrm{~mm}$ in diameter and $150 \mathrm{~mm}$ in height, and there is a $6 \mathrm{~mm}$ diameter hole at the centre which was realized by inserting a stainless steel rod when we casted the specimen and carefully extracting the rod when the specimen gradually hardened. The tank is full of $\mathrm{NaCl}$ solution which was configured with deionized water. Nitrogen was used to control

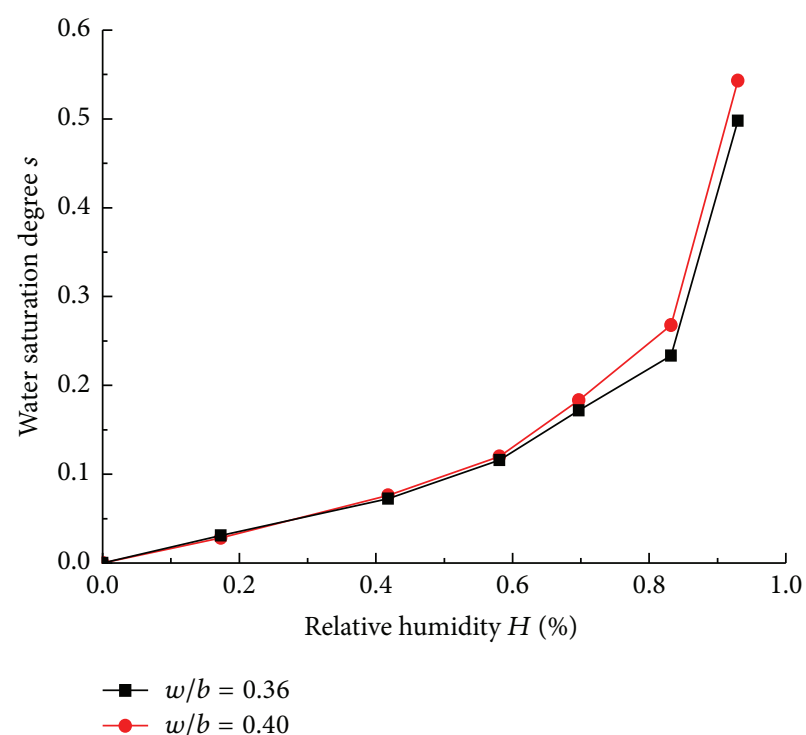

FIGURE 1: Isothermal adsorption curves for the concrete mixtures.

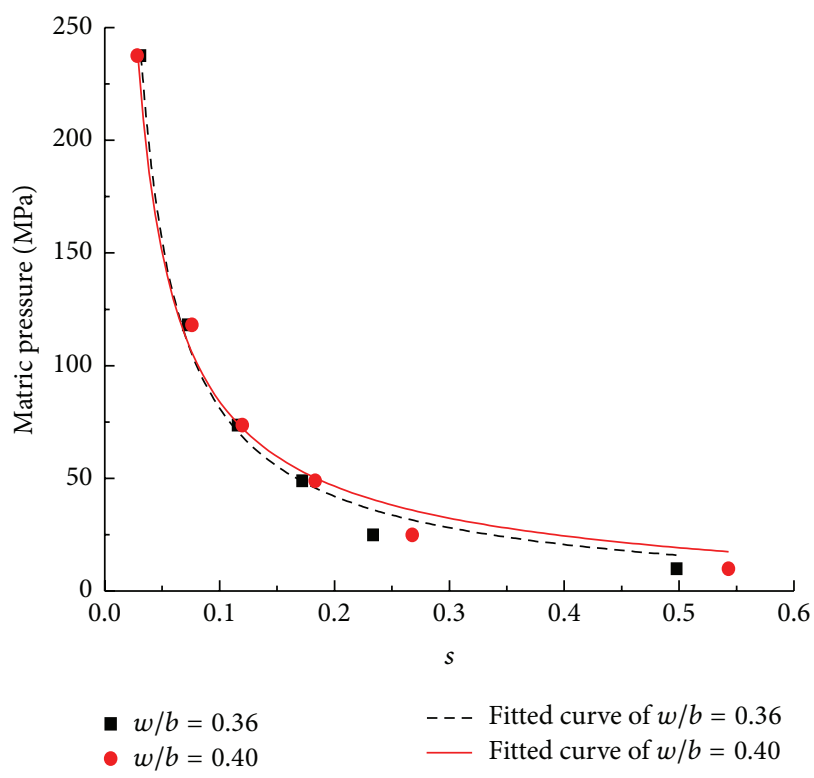

Figure 2: Moisture characteristic curves for the concrete mixtures.

TABLE 5: Regression parameters $(\alpha, m)$ and correlation coefficients $\left(R^{*}\right)$ of moisture characteristic curves for concrete mixtures.

\begin{tabular}{lcccc}
\hline Number & $w / b$ & $\alpha / \mathrm{MPa}$ & $m$ & $R^{* 2}$ \\
\hline BI & 0.36 & 9.662 & 0.519 & 0.991 \\
BII & 0.40 & 12.576 & 0.554 & 0.988 \\
\hline
\end{tabular}

the water pressure and push the $\mathrm{NaCl}$ solution in the tank applying on the internal hole wall of specimens. So the inner side of the specimen is equivalent to the outer wall of subsea tunnel bearing hydraulic pressure; oppositely, the outer side of the specimen is equivalent to the inner wall of subsea tunnel bearing atmospheric pressure. 


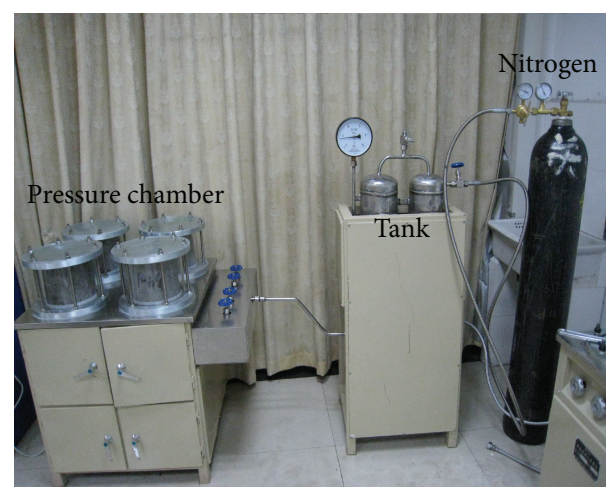

FIgURE 3: Chloride penetration tester.

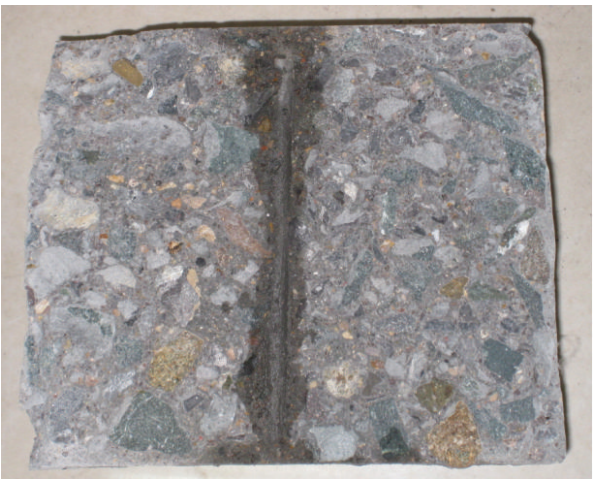

FIGURE 4: Solution transport diagram.
TABLE 6: Working conditions of chloride transport tests.

\begin{tabular}{lcccc}
\hline $\begin{array}{l}\text { Working } \\
\text { conditions }\end{array}$ & $\begin{array}{c}\text { Specimens } \\
\text { number }\end{array}$ & $\begin{array}{c}\text { Pressure } \\
(\mathrm{MPa})\end{array}$ & $X_{\mathrm{NaCl}}$ & $\begin{array}{c}\text { Pressuring } \\
\text { time }(\mathrm{h})\end{array}$ \\
\hline 1 & BII-1 & 1.5 & $3 \%$ & 72 \\
2 & BII-1 & 1.5 & $15 \%$ & 168 \\
3 & BII-1 & 1.5 & $15 \%$ & 72 \\
4 & BII-2 & 1.5 & $15 \%$ & 72 \\
5 & BII-3 & 1.5 & $15 \%$ & 72 \\
6 & BI & 1 & $15 \%$ & 72 \\
7 & BI & 1.5 & $15 \%$ & 72 \\
8 & BI & 2 & $15 \%$ & 72 \\
\hline
\end{tabular}

$X_{\mathrm{NaCl}}$ : concentration of $\mathrm{NaCl}$ solution.

The working conditions are shown in Table 6. Experimental procedure is as follows:

(1) Place a $1 \mathrm{~cm}$ thickness silicone gasket with $\phi 6 \mathrm{~mm}$ central hole on the bottom of pressure chamber. Then place a concrete specimen on the silicone gasket with the central hole aligned. After that, place an intact silicone gasket on the top of the specimen and cover a $2 \mathrm{~cm}$ thickness stainless steel plate. Hereafter, tighten the plate with six steel rods to fix the specimen.

(2) Open the valve of nitrogen bottle and adjust pressure to the designated value.

(3) When the pressure reading is stable, then open the valve of the tank to supply pressure water which penetrates into concrete through the preformed hole of specimens. Until the scheduled pressuring time is reached, turn off the valve of the tank.

(4) Take the specimen out from the chamber and split it along the diameter using a Universal Testing Machine (Figure 4). Use hammer and drill to drill samplings every $15 \mathrm{~mm}$ along the radial direction of the splitting specimen. After crushing the samplings into fine powders and mixing with deionized water, we measure the chloride concentration of the mixtures by means of RCT (Rapid Chloride Test). Since the drill has a certain size, the chloride concentration is an average value around the sampling location.
From Figure 4, it is easy to find that obvious saturated zone and unsaturated zone formed after solution penetrating into concrete from fabricated holes. Solution penetration depth is uniform on the whole along the height direction except top and bottom of specimens because it is difficult to be absolutely sealed. The result indicates solution velocity is basically the same in height, so the influence of gravity potential can be ignored to such low specimens. Though the solution penetration depth in Figure 4 is shallow (it depends on pressuring time, external pressure, and initial saturation [16]), Figures 5-7 show that chloride penetration depth is larger, which means chloride can migrate in concrete under unsaturated state.

3.5. Results and Discussion. From the chloride concentration profiles (Figures 5-7), we found that chloride concentration declined with depth and increased with pressuring time. Figure 5 showed the influence of solution concentration and pressuring time on chloride transport under the same hydraulic pressure of $1.5 \mathrm{MPa}$ and initial saturation of 0.718 (working conditions 1-3). It is easy to see that solution concentration greatly affects chloride concentration and distribution (Figure 5). The concrete with higher solution concentration showed higher chloride concentration at a given depth and steeper curve compared to the concrete with lower concentration at the same time. Meanwhile, besides the growth of chloride concentration with time inside the concrete, the surface chloride concentration also accumulated with time. It demonstrated that diffusion was a key factor for chloride transport, and the larger the difference of chloride concentration was, the faster the chloride transported from the higher concentration to the lower concentration. Under working conditions 3,4 , and 5 with the same solution concentration of $15 \%$ and water pressure of $1.5 \mathrm{MPa}$, Figure 6 showed that the lower the initial saturation was, the higher the chloride concentration was at a given depth. It means that capillary suction associated with saturation is another factor for chloride transport. Figure 7 showed that hydraulic pressure also affected chloride transportation under the same solution concentration of $15 \%$ and initial saturation of 0.715 (working conditions 6-8). The higher the water pressure was, the higher the chloride concentration was at a given depth. Initial saturation 


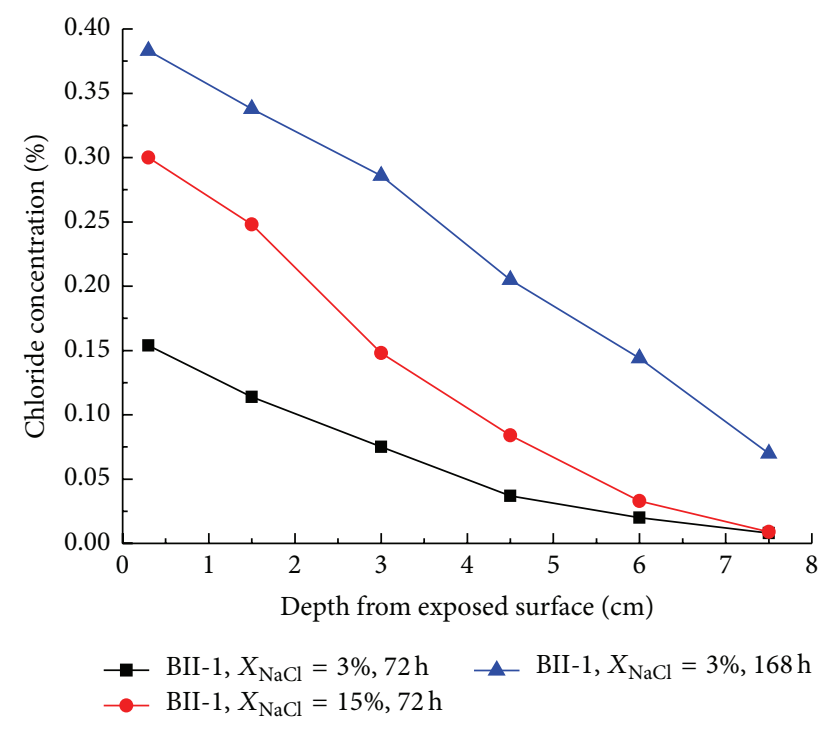

FIGURE 5: Chloride concentration profile under different pressuring time and solution concentration.

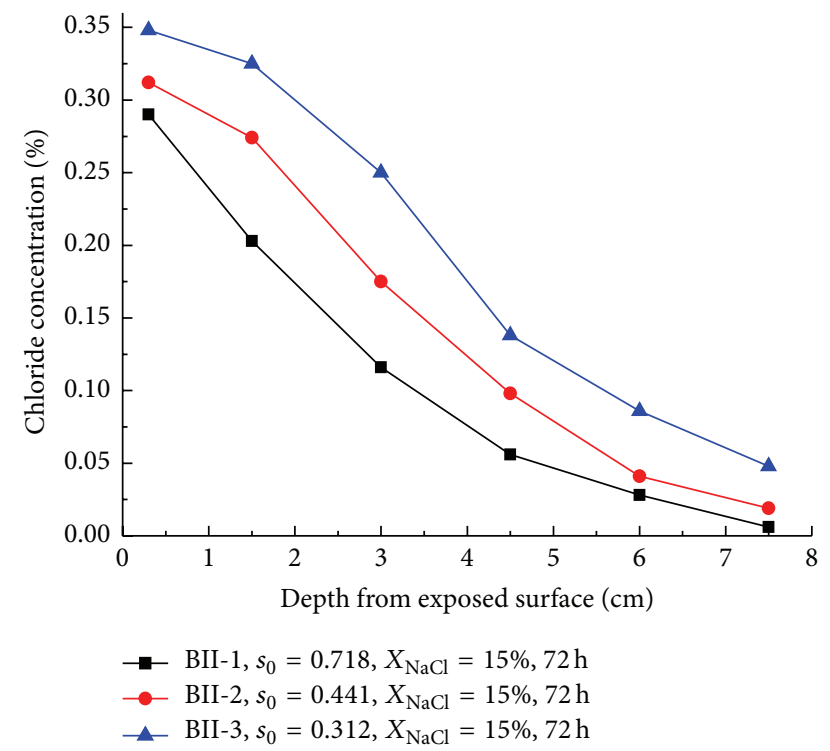

FIGURE 6: Chloride concentration profile under different initial saturation.

and water pressure showed the same influence on water penetration with the above results based on lab experiments and numerical simulations [16], so we believe the experimental results of chloride transport affected by initial saturation and water pressure were a result of chloride advection which depended on pore solution's motion. Hence, diffusion and advection are coresponsible for chloride transportation instead of only diffusion in aforementioned references.

Comparing curve $\boldsymbol{\square}$ in Figure 6 and curve in Figure 7, we can find that chloride concentration at the same time in $\mathrm{BI}$ is smaller than that in BII-1 under the same pressuring time $(t=72 \mathrm{~h})$, water pressure $\left(P_{0}=1.5 \mathrm{MPa}\right)$, solution concentration $\left(X_{\mathrm{NaCl}}=15 \%\right)$, and similar initial saturation

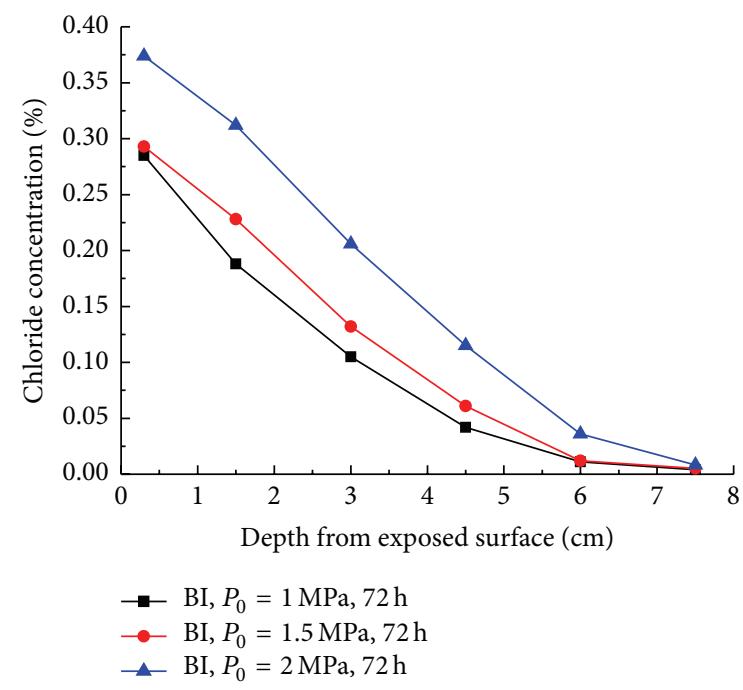

Figure 7: Chloride concentration profile under different hydraulic pressure.

$\left(s_{0}=0.718\right.$ and $\left.s_{0 \bullet}=0.715\right)$. It showed that water-binder ratio also affected chloride transport because the lower the water-binder ratio was, the denser the concrete was, and as a result chloride ions more difficultly migrated.

We take working conditions 6-8, for example, to discuss the process of chloride transport, which can be divided into three stages.

(1) Initial Pressuring Stage. Considering $\mathrm{NaCl}$ solution penetrating into concrete through the wall of preformed hole, we can deem that a very thin fully saturated layer exists on the hole wall with driving potential of $\psi(x=0.003 \mathrm{~m})=\psi_{p}=P_{0}$, while the inside zone is still unsaturated at the initial stage, so $\psi(0.003 \mathrm{~m}<x \leq 0.1 \mathrm{~m})=\psi_{m}=-9.23 \mathrm{MPa}$. Obviously $\nabla \psi$ increases with the increase of hydraulic pressure $P_{0}$ on hole wall. The higher $\nabla \psi$ induces faster solution velocity (see (7)) and larger advection flux (see (5)). In addition, diffusion flux is the same at this time due to the same solution concentration. So the higher the hydraulic pressure on hole wall is, the higher the surface chloride concentration is.

(2) Specimens under Unsaturated State after Pressuring. When $\mathrm{NaCl}$ solution penetrates into unsaturated zone through the hole wall, faster initial solution velocity accelerates saturation degree of concrete near inlet surface rapidly increasing, which results in matric potential $\psi_{m}$ decline faster (see (10)). As a result, $\nabla \psi$ becomes larger for the dramatic decline of $\psi_{m}$, which makes solution transport further faster (see (7)). Meanwhile, relative hydraulic conductivity $k_{r}$ increases with saturation degree according to (8). That is, larger pressure induces larger saturation degree, solution velocity, and advection flux. In addition, because surface chloride concentration is larger with higher water pressure $P_{0}$, larger chloride concentration difference will result in larger diffusion flux. Hence the higher the water pressure is, the larger the chloride concentration is at this stage. 
(3) Specimens with Saturated Zone after Pressuring. Fully saturated zone was first formed in specimen under higher $P_{0}$ condition with pressuring time. Then matric potential $\psi_{m}$ becomes zero and chloride transport is controlled by pressure potential $\psi_{p}$. We notice that $\psi_{p}$ increases with $P_{0}$ (see (11)), so it is believed that larger pressure will lead to faster solution velocity in saturated zone (see (6)), which drives chloride ions faster transport towards the unsaturated zone. Meanwhile, concentration difference between saturated zone and inside unsaturated zone gradually increases, which results in larger chloride diffusion flux. Hence the higher the water pressure is, the larger the chloride concentration is at this stage.

Thus, diffusion-advection theoretical model of chloride can explain the experimental results of chloride concentration increases with water pressure in Figure 7.

As for specimens with different initial saturation $s_{0}$ and the same $P_{0}$ and $X_{\mathrm{NaCl}}$ (working conditions 3-5), the total driving potential $\psi=\psi_{p}=1.5 \mathrm{MPa}$ on the saturated hole wall at the initial pressuring stage, while in the unsaturated zone near saturated surface $\psi$ is equal to matric potential $\psi_{m}$. Because saturation degree has inverse relationship with $\psi_{m}$ (see (10)), the lower the initial saturation is, the larger $\nabla \psi$ is and, correspondingly, the higher the solution velocity, advection flux, and chloride concentration are. Meanwhile, with the increase of chloride concentration difference, diffusion flux increases too. Thus, these can explain why specimen with lower initial saturation has higher chloride concentration in Figure 6.

As for specimens with different solution concentration $X_{\mathrm{NaCl}}$ and the same $P_{0}$ and $s_{0}$ (working condition 1-3), the pressure potential and matric potential are the same at the initial stage, while chloride concentration difference between saturated surface and inside unsaturated zone is different. Obviously, the higher the solution concentration is, the larger the chloride concentration difference and diffusion flux are, which correspondingly results in the increase of chloride concentration inside. These can be used to explain the experimental results of chloride concentration increases with solution concentration in Figure 5.

\section{Numerical Analysis}

The EOS9 module and EWASG module of TOUGH2 software were used to run the numerical simulation, which could simulate water and chloride ions transport, respectively [29]. Considering that the height of the specimens is low in our tests, so we only simulated isothermal horizontal flow without considering gravity potential.

The numerical simulation was carried out on $200 \mathrm{~mm}$ diameter, $150 \mathrm{~mm}$ height cylinder model with $\phi 6 \mathrm{~mm}$ central hole (Figure 8). The model was discretized into ring-shaped elements with $0.001 \mathrm{~m}$ thickness from $0.003 \mathrm{~m}$ to $0.05 \mathrm{~m}$ and with $0.005 \mathrm{~mm}$ thickness from $0.05 \mathrm{~m}$ to $0.1 \mathrm{~m}$. The initial chloride concentration was supposed as zero. The inside boundary was set as time-varying concentration boundary for the surface chloride concentration accumulated with time in experiments. It could be realized by setting a sourcesink term on the boundary and the source flow velocity was obtained by EOS9 module simulation [16]. Meanwhile, the

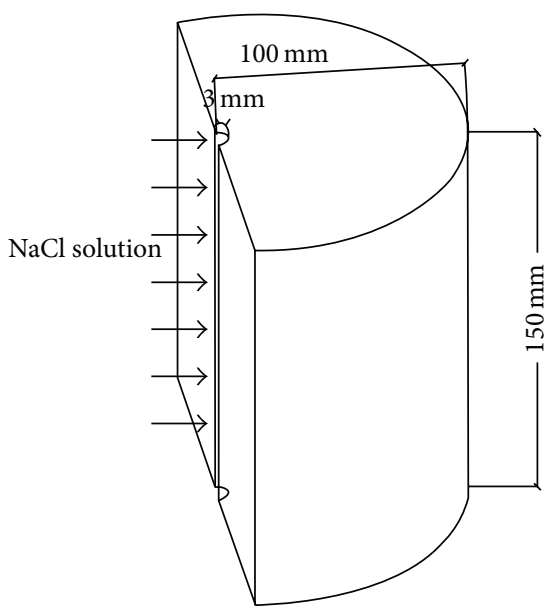

Figure 8: Schematic diagram for half of the model.

outside boundary was modeled as atmospheric condition subjected to a barometric pressure of $P_{0}=1.013 e 5 \mathrm{~Pa}$. The top and bottom boundaries were modeled as no flow boundaries to simulate the sealing effect of silicone gaskets. Atkinson and Milling-Quirk models were adopted to calculate the chloride diffusion coefficient with saturation, in which $D_{\text {RCM }}$ from laboratory experiment was taken as saturated diffusion coefficient $D_{s_{0}}$ in (3). Other input parameters in the model were taken from the above experimental results.

It is noteworthy that the unit of chloride concentration is volume concentration of pore liquid $\left(\mathrm{kg} / \mathrm{m}^{3}\right)$ in theoretical analysis and numerical simulation, while it is expressed as mass percent of concrete powder (\%) in RCT test. Thus, we should change the unit of chloride concentration from volume concentration into mass percent concentration if quantitatively comparing the results of simulations with those of experiments. The unit conversion formula can be written as

$$
C_{f \%}=\frac{1 \times \phi \times s \times \rho_{w} \times C_{f}}{1 \times \rho_{c}} \times 100 \%,
$$

where $C_{f \%}$ is the mass percent concentration of chloride, \%; $\rho_{c}$ is the concrete density, $\mathrm{kg} / \mathrm{m}^{3}$; the volume concentration of chloride $C_{f}$ and water saturation $s$ can be calculated by EWASG module.

From (16) we realize that it is difficult to accurately establish the conversion relationship between simulations and experiments. Firstly, porosity used in EWASG is obtained by boiling test [25] which is an average value of the concrete specimens, but the real distribution of capillary pores in specimens is uneven, furthermore, only part of which is completely interconnected for chloride transportation. Secondly, the ion-combination of chloride with concrete under high external pressure is not clear at present, so the actual free chloride concentration on concrete boundary in tests is unknown, which led to an error in boundary concentration when simulating; meanwhile, the influence of ion-combination on the concentration inside is also undeterminable. Finally, the chloride concentration measured by RCT is an average value around the sampling location while the 


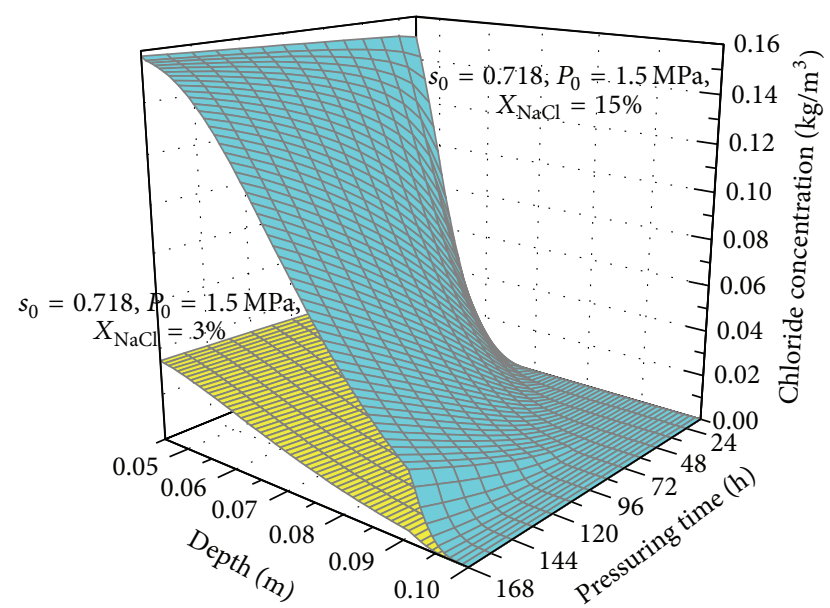

FIGURE 9: Chloride concentration simulation under different solution concentration.

simulation result is at a specific depth. For the above reasons the simulation results based on the assumptions that all the capillary pores are uniform distributions and fully connected and there are no ion-combination reactions with chloride ions led to a large difference with that of laboratory experiments. So we only qualitatively compare the chloride concentration trend between simulations and experiments.

4.1. Influence of Solution Concentration. From Figure 9 simulated with different solution concentrations under $s_{0}=0.718$ and $P_{0}=1.5 \mathrm{MPa}$, we found that the trend of concentration in simulation was consistent with the experimental results (Figure 5). That is, chloride concentration is not only decreased with depth and increased with time, but also accumulated with time on the boundary. The higher solution concentration caused the higher chloride concentration, the steeper variation gradient, and the farther transport distance. The results reflected that chloride was nonsteady diffusion in model and the larger the difference of chloride concentration was, the faster the chloride moved. We also noticed that the increase of chloride concentration slowed down with time in simulation which was fit with the experiment results in Figure 5. The main reason is the difference of chloride concentration gradually reduced with the increase of interior concentration.

4.2. Influence of Initial Saturation. The effect of initial saturation on chloride transport was studied by running examples where the initial saturation varied with $0.312,0.718$, and 1 under $P_{0}=1.5 \mathrm{MPa}$ and $X_{\mathrm{NaCl}}=15 \%$. It is observed that both of chloride concentration and penetration depth raised with the decrease of saturation and the increase of time (Figure 10), which was consistent with the experimental results (Figure 6) and the simulation results from Kumar [30]. We also noted that the change of chloride concentration is flatter near the inner boundary for the lower saturation degree than the higher saturation. Indeed, the experimental results (Figure 6) also showed the same trend. This is mainly because the lower

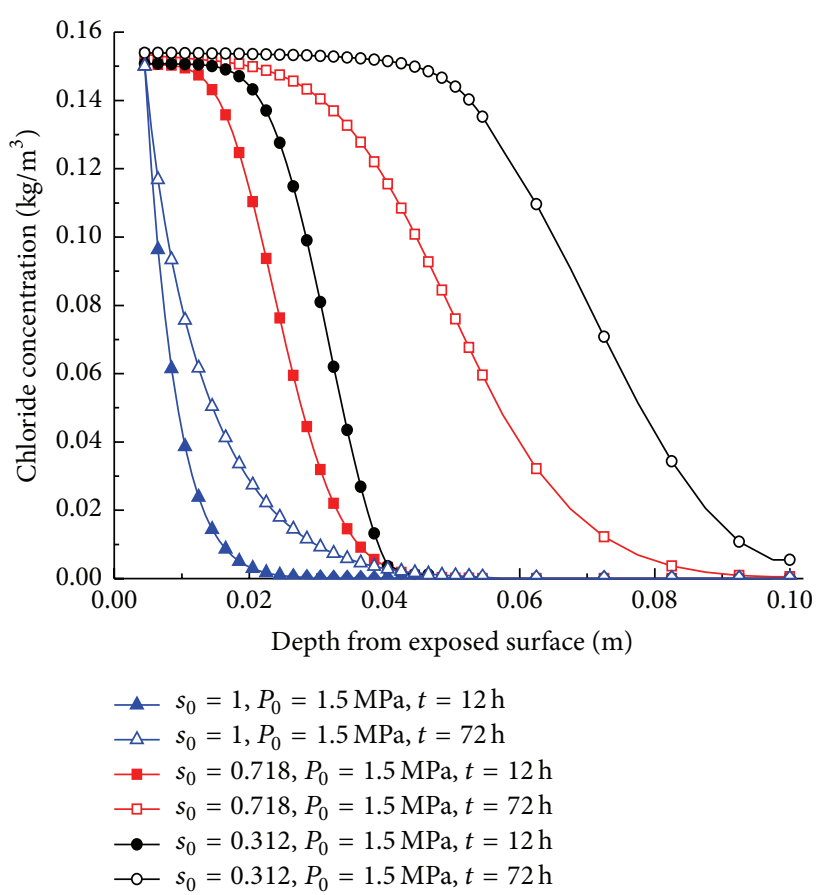

FIGURE 10: Chloride concentration simulation under different initial saturation.

the saturation is, the higher the matric potential is, which can result in faster solution velocity and higher saturation and chloride concentration.

If the capillary suction is neglected (set $s_{0}=1$, i.e., fully saturated concrete), the simulation concentration is far lower than that in unsaturated concrete because the pressure potential $\left(\psi_{p_{0}}=1.5 \mathrm{MPa}\right)$ is much less than the matric potential $\left(s_{0}=0.312, \psi_{m_{0}}=-30.3 \mathrm{MPa}\right.$ and $s_{0}=0.718, \psi_{m_{0}}=$ $-11.5 \mathrm{MPa}$ ). The simulations emphasize the importance of water flow and chloride transportation in unsaturated conditions when predicting service life of subsea concrete structures.

4.3. Influence of Water Pressure. To study the influence of water pressure on chloride penetration, only water pressure was varied while maintaining the initial saturation as 0.715 and initial surface chloride concentration as $15 \%$ with sample block BI. The results of numerical analysis are shown in Figure 11, which can denote that the simulation results were fit with the former experiments (Figure 7) and the experimental results from Jin et al. [14] and Chen [15]; that is, chloride concentration and penetration depth increased with the increase of water pressure. The results can be explained by the discussion in Section 3.5. We also noted that the influence of water pressure on chloride concentration became more significant with time comparing the concentration curve interval between $12 \mathrm{~h}$ and $72 \mathrm{~h}$ (Figure 11). This is mainly because water pressure controlled a small region attached to saturated surface layer at first; however water pressure played more important role instead of capillary suction with the expansion of saturated zone. 


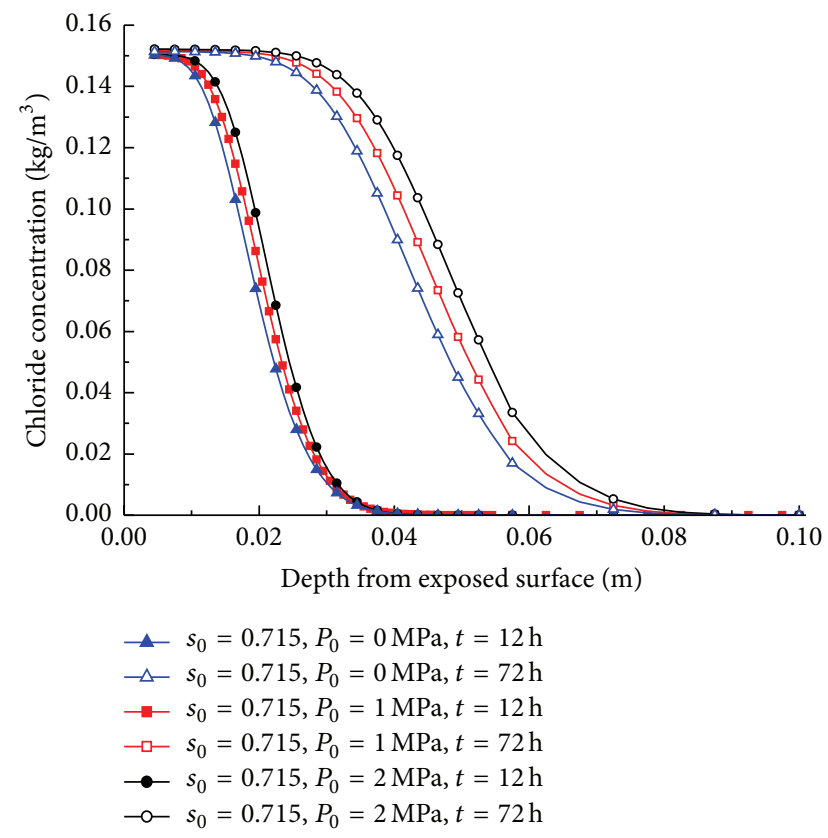

FIGURE 11: Chloride concentration simulation under different hydraulic pressure.

If water pressure is neglected (set $P_{0}=0 \mathrm{MPa}$ ), the chloride concentration is lower than the results subjected to hydraulic pressure (1 $\mathrm{MPa}$ and $1.5 \mathrm{MPa})$. Obviously, the rate of concentration decline is very significant in Section 4.2 ignoring the effect of capillary pressure, because the difference of driving potential is larger. Thus, the durability design of subsea tunnel should consider the hydraulic pressure; otherwise the durability tends to be unsafe.

\section{Conclusion}

Theoretical models of chloride diffusion-advection in unsaturated concrete of undersea tunnel were established. The variations of chloride concentration with pressuring time, location, solution concentration, initial saturation, hydraulic pressure, and water-binder ratio were investigated through penetration tests under external water pressure. In addition, the change and distribution of chloride concentration were numerically analyzed using TOUGH2 software. The results show the following.

(1) Chloride transport under external water pressure in unsaturated concrete is a combined effect of diffusion and advection, where diffusion is driven by the difference of concentration and advection is driven by capillary suction and hydraulic pressure. Hence, for the subsea concrete tunnels which withstand hydraulic pressure on outside wall and atmospheric pressure on inside wall, chloride transport is affected by diffusion, capillary suction, and external pressure instead of diffusion.

(2) Chloride concentration in concrete declined with depth and increased with time. The higher the difference of chloride concentration is, the higher the chloride concentration is. Meanwhile it shows that the higher the hydraulic pressure and the lower the initial saturation of concrete, the higher the chloride concentration. The change of chloride concentration slowed down with time because the concentration difference declined for the concentration growth and the smaller driving potential of pressure replaced the larger driving potential of capillary suction with the saturation growth.

(3) Service life of undersea concrete tunnel will be overpredicted if only chloride diffusion in tunnel based on the full saturated concrete hypothesis is considered. Because advection plays an important role in chloride transport of undersea tunnel, the effect of capillary suction and water pressure on the durability design of subsea tunnel should be taken into consideration; otherwise it tends to be unsafe.

\section{Competing Interests}

The authors declare that they have no competing interests.

\section{Acknowledgments}

This work was supported by the National Natural Science Foundation of China (no. 51208463), Natural Science Foundation of Zhejiang Province of China (no. LY12E08012), and Jinhua Technology Bureau Research (2015-3-050).

\section{References}

[1] W. H. Dunagan, "Methods for measuring the passage of water through concrete," in Proceedings of the American Society for Testing Materials, vol. 39, pp. 866-880, ASTM International, West Conshohocken, Pa, USA, 1939.

[2] H. M. Chen, F. X. Sun, and Y. F. Wang, "Service life prediction of Xiamen Xiang'an subsea tunnel lining structure," in Proceedings of the International Conference on Durability of Concrete Structures, pp. 992-997, Hangzhou, China, November 2008.

[3] H.-W. Song, S.-W. Pack, and K. Y. Ann, "Probabilistic assessment to predict the time to corrosion of steel in reinforced concrete tunnel box exposed to sea water," Construction and Building Materials, vol. 23, no. 10, pp. 3270-3278, 2009.

[4] J. Sun, "Durability problems of lining structures for Xiamen Xiang'an subsea tunnel in China," Journal of Rock Mechanics and Geotechnical Engineering, vol. 3, no. 4, pp. 289-301, 2011.

[5] T. C. Powers and T. L. Brownyand, "Studies of the physical properties of hardened portland cement paste," ACI Journal Proceedings, vol. 43, no. 9, pp. 249-336, 1946.

[6] C. Hall, "Water sorptivity of mortars and concretes: a review," Magazine of Concrete Research, vol. 41, no. 147, pp. 51-61, 1989.

[7] B. Persson, "Moisture in concrete subjected to different kinds of curing," Materials and Structures, vol. 30, no. 203, pp. 533-544, 1997.

[8] C. Leech, D. Lockington, and P. Dux, "Unsaturated diffusivity functions for concrete derived from NMR images," Materials and Structures, vol. 36, no. 7, pp. 413-418, 2003.

[9] L.-O. Nilsson, "Long-term moisture transport in high performance concrete," Materials and Structures, vol. 35, no. 254, pp. 641-649, 2002. 
[10] A. V. Saeta, R. V. Scotta, and R. V. Vitaliani, "Analysis of chloride diffusion into partially saturated concrete," ACI Materials Journal, vol. 90, no. 5, pp. 441-451, 1993.

[11] A. Ababneh, F. Benboudjema, and Y. P. Xi, "Chloride penetration in nonsaturated concrete," Journal of Materials in Civil Engineering, vol. 15, no. 2, pp. 183-191, 2003.

[12] P. O'Neill Iqbal and T. Ishida, "Modeling of chloride transport coupled with enhanced moisture conductivity in concrete exposed to marine environment," Cement and Concrete Research, vol. 39, no. 4, pp. 329-339, 2009.

[13] Z. Zhang, M. Thiery, and V. Baroghel-Bouny, "Numerical modelling of moisture transfers with hysteresis within cementitious materials: verification and investigation of the effects of repeated wetting-drying boundary conditions," Cement and Concrete Research, vol. 68, pp. 10-23, 2014.

[14] Z.-Q. Jin, T.-J. Zhao, S. Gao, and B.-R. Hou, "Chloride ion penetration into concrete under hydraulic pressure," Journal of Central South University, vol. 20, no. 12, pp. 3723-3728, 2013.

[15] C. Chen, Study on durability of underground concrete structures in chloride environment [Ph.D. dissertation], Tongji University, Shanghai, China, 2009 (Chinese).

[16] Y. Z. Zhang, X. Z. Li, X. J. Wei, G. Yu, W. Li, and Y. Huang, "Water penetration in underwater concrete tunnel," Journal of the Chinese Ceramic Society, vol. 43, no. 4, pp. 368-375, 2015 (Chinese).

[17] A. Atkinson and A. K. Nickerson, "The diffusion of ions through water-saturated cement," Journal of Materials Science, vol. 19, no. 9, pp. 3068-3078, 1984.

[18] R. J. Millington and J. P. Quirk, "Permeability of porous solids," Transactions of the Faraday Society, vol. 57, pp. 1200-1207, 1961.

[19] Y. Mualem, "A new model for predicting the hydraulic conductivity of unsaturated porous media," Water Resources Research, vol. 12, no. 3, pp. 513-522, 1976.

[20] Y. Mualem, "Hysteresis models for prediction of the hydraulic conductivity of unsaturated porous media," Water Resources Research, vol. 12, no. 6, pp. 1248-1254, 1976.

[21] M. T. van Genuchten, "Closed-form equation for predicting the hydraulic conductivity of unsaturated soils," Soil Science Society of America Journal, vol. 44, no. 5, pp. 892-898, 1980.

[22] J.-H. Yoo, H.-S. Lee, and M. A. Ismail, "An analytical study on the water penetration and diffusion into concrete under water pressure," Construction and Building Materials, vol. 25, no. 1, pp. 99-108, 2011.

[23] A. Ogata and R. B. Banks, A Solution of the Differential Equation of Longitudinal Dispersion in Porous Media, US Department of Interior, Washington, DC, USA, 1961.

[24] "Standard for test method of mechanical properties on ordinary concrete," Tech. Rep. GB/T 50081-2002, China Architecture \& Building Press, Beijing, China, 2003 (Chinese).

[25] ASTM C642, Standard Test Method for Density, Absorption, and Voids in Hardened Concrete, Annual Book of ASTM Standards, Philadelphia, Pa, USA, 2002.

[26] Chinese Standard, “Test code for hydraulic concrete," Tech. Rep. SL352-2006, China Electric Power Press, Beijing, China, 2006 (Chinese).

[27] GB/T 50082-2009, Standard for Test Methods of Long-Tem Performance and Durability of Ordinary Concrete, China Architecture \& Building Press, Beijing, China, 2010 (Chinese).

[28] C. Q. Li and K. F. Li, "Moisture transport in concrete cover under drying-wetting cycles: theory, experiment and modeling," Journal of the Chinese Ceramic Society, vol. 38, no. 7, pp. 1151-1159, 2010 (Chinese).
[29] K. C. Pruess and O. G. Moridis, “TOUGH2 user's guide (version 2.0)," Tech. Rep. LBNL-43134, Lawrence Berkeley National Laboratory, 1999.

[30] A. Kumar, Water Flow and Transport of Chloride in Unsaturated Concrete, University of Saskatchewan, Saskatoon, Canada, 2010. 

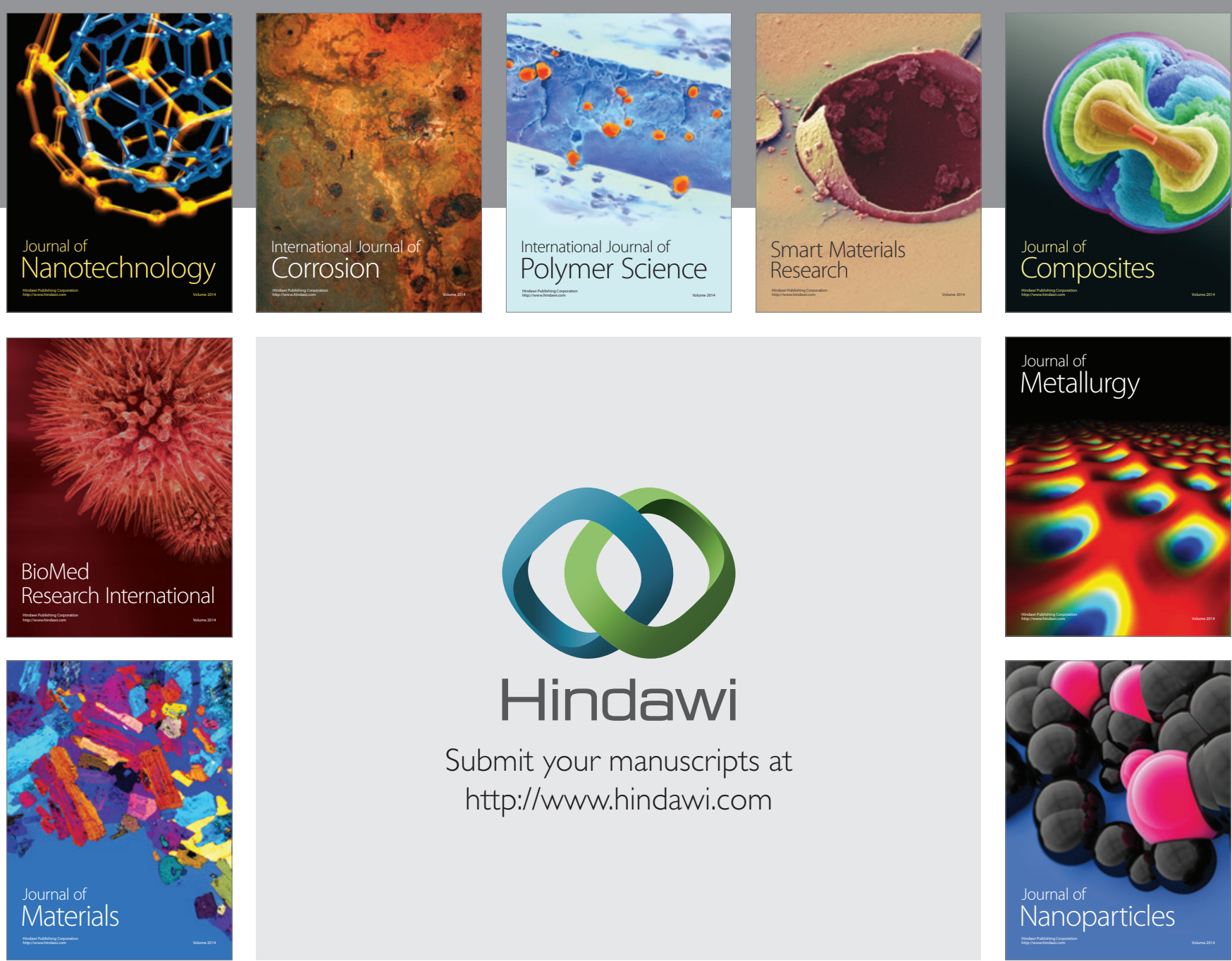

\section{Hindawi}

Submit your manuscripts at

http://www.hindawi.com

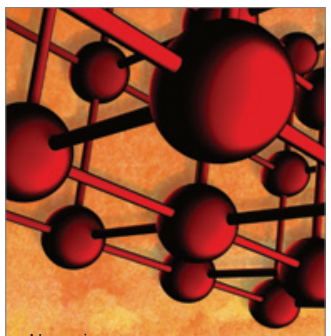

Materials Science and Engineering
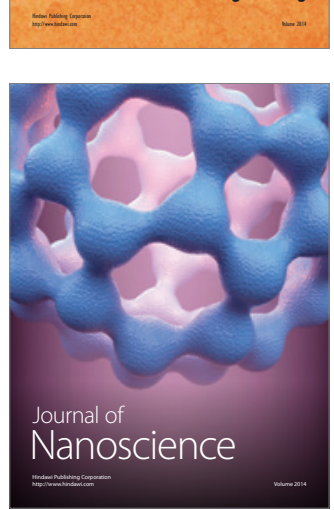
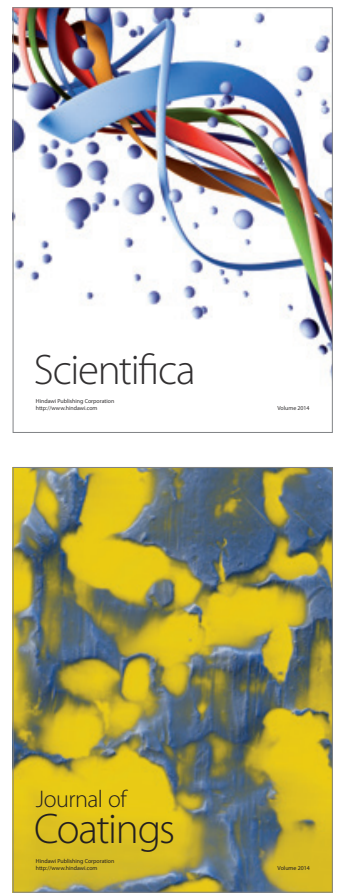
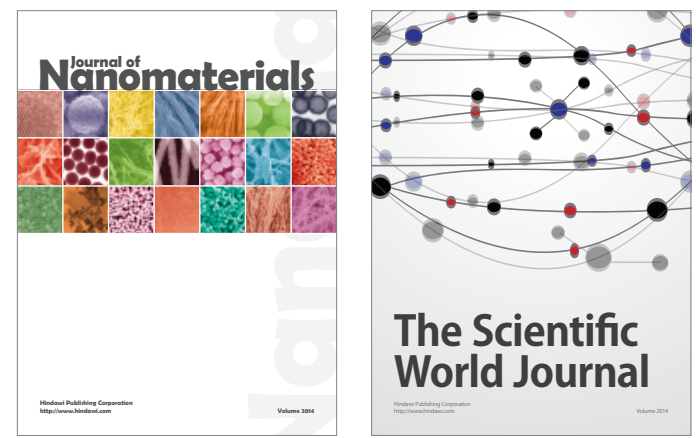

The Scientific World Journal
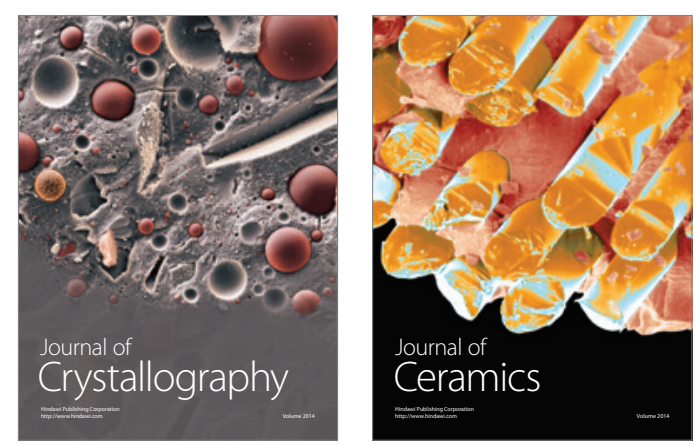
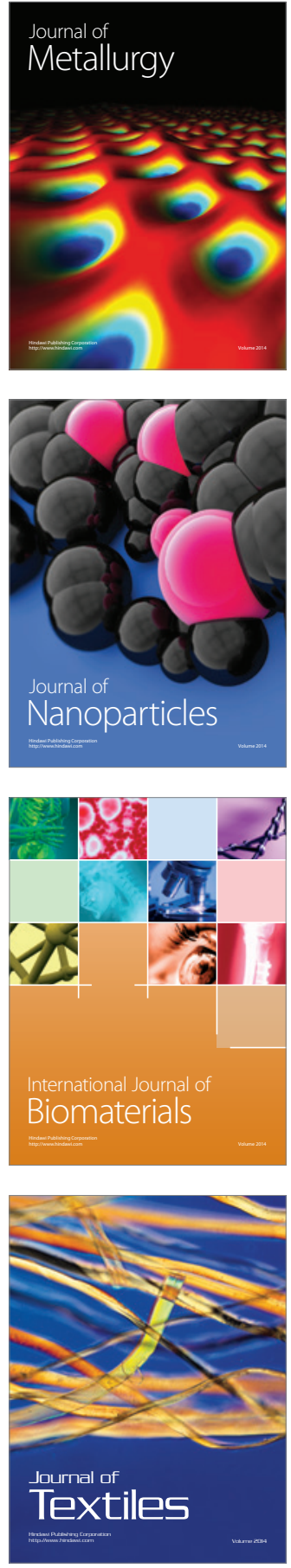